\title{
THE CONTRIBUTION OF ELECTRICAL CONDUCTIVITY, DIELECTRIC PERMITTIVITY AND DOMAIN SWITCHING IN FERROELECTRIC HYSTERESIS LOOPS
}

\author{
HAIXUE YAN $^{*, \dagger}, \boldsymbol{\uparrow}$, FAWAD INAM $^{*, \dagger}$, GIUSEPPE VIOLA*,†, \\ HUANPO NING ${ }^{*, \dagger}$, HONGTAO ZHANG ${ }^{*, \dagger}$, QINGHUI JIANG ${ }^{\S}$, \\ TAO ZENG*, ZHIPENG GAO* and MIKE J REECE*,,,$\|$ \\ *School of Engineering and Materials Science \\ Queen Mary University of London \\ Mile End Road, London, E1 4NS, UK \\ ${ }^{\dagger}$ Nanoforce Technology Ltd, Mile End Road \\ London, E1 $4 N S$, UK \\ ${ }^{\ddagger}$ Department of Materials, University of Oxford \\ Oxford, OX1 3PH, UK \\ ${ }^{\S}$ School of Materials Science and Engineering \\ University of Jinan, Shandong 250022, P. R. China \\ \h.x.yan@qmul.ac.uk \\ "Im.j.reece@qmul.ac.uk
}

Received 23 September 2010

Revised 11 October 2010

\begin{abstract}
Triangular voltage waveform was employed to distinguish the contributions of dielectric permittivity, electric conductivity and domain switching in current-electric field curves. At the same time, it is shown how those contributions can affect the shape of the electric displacement electric field loops ( $D-E$ loops). The effects of frequency, temperature and microstructure (point defects, grain size and texture) on the ferroelectric properties of several ferroelectric compositions is reported, including: $\mathrm{BaTiO}_{3}$; lead zirconate titanate (PZT); lead-free $\mathrm{Na}_{0.5} \mathrm{~K}_{0.5} \mathrm{NbO}_{3}$; perovskite-like layer structured $\mathrm{A}_{2} \mathrm{~B}_{2} \mathrm{O}_{7}$ with super high Curie point $\left(T_{\mathrm{c}}\right)$; Aurivillius phase ferroelectric $\mathrm{Bi}_{3.15} \mathrm{Nd}_{0.85} \mathrm{Ti}_{3} \mathrm{O}_{12}$; and multiferroic $\mathrm{Bi}_{0.89} \mathrm{La}_{0.05} \mathrm{~Tb}_{0.06} \mathrm{FeO}_{3}$. This systematic study provides an instructive outline in the measurement of ferroelectric properties and the analysis and interpretation of experimental data.
\end{abstract}

Keywords: Polarization; ferroelectrics; conductivity; permittivity; domain.

\Corresponding author. 


\section{Introduction}

The development of ferroelectric ceramics started with the discovery of the ferroelectric oxide $\mathrm{BaTiO}_{3}$ during the early 1940s. ${ }^{1,2}$ Since then, many different ferroelectric materials have been developed to satisfy technological requirements in many different applications. $^{3-5}$

The most important characteristic of ferroelectric materials is their ability to reverse their polarization state under the application of an electric field, which determines their characteristic electric displacement-electric field $(D-E)$ hysteresis loop. ${ }^{5-10}$ $D-E$ loop measurements are performed by applying an ac voltage to a ferroelectric sample. The electric displacement $D$ is obtained by integrating the current with respect to time and by dividing the value obtained by the area of the sample. The electric displacement $D$ includes contributions from ferroelectric domain switching $P$, electric conductivity $D 1$ and dielectric displacement $D 2=\varepsilon E=\varepsilon_{\mathrm{r}} \varepsilon_{\mathrm{o}} E$, where $\varepsilon_{\mathrm{o}}=8.854 \times 10^{-12} \mathrm{~F} / \mathrm{m}$ is the dielectric permittivity of the vacuum and $\varepsilon_{\mathrm{r}}$ is the relative permittivity of a material. It is often the case that $D-E$ loops are presented as $P-E$ loops without the subtraction of the dielectric and conductivity because the contribution from $D 1$ and $D 2$ are relatively small. The measurement of the $D-E$ loops is fundamental to characterize ferroelectric properties. Although several authors have provided some guidelines for their analysis, ${ }^{3,7,11,12}$ inaccuracies and misinterpretations are still frequent in the literature. Simple $D-E$ loop measurements are not always sufficient to confirm the presence of ferroelectricity, especially in low dimensional structures such as thin films and nanograined materials. ${ }^{12}$ In addition, $D-E$ hysteresis loop measurements can be affected by artefacts produced by back-to-back diodes. ${ }^{12}$ These artefacts can give rise to apparent hysteresis curves which are partially or not at all related to ferroelectricity. ${ }^{11,12}$ Such interpretation produces meaningless assessment of the ferroelectric nature of the system studied and significant errors in the estimation of the most important ferroelectric properties, such as coercive field and remnant polarization.

In this paper, different ferroelectric materials were characterized to illustrate the contribution of electric conductivity, dielectric permittivity and ferroelectric domain switching to $D-E$ loops. High electric resistivity $\mathrm{Al}_{2} \mathrm{O}_{3}$ ceramic, previously characterized, ${ }^{13}$ was used to demonstrate the pure contribution of dielectric permittivity in $D-E$ loops. The selected ferroelectric materials included: doped $\mathrm{BaTiO}_{3}$; PZT; lead-free $\mathrm{Na}_{0.5} \mathrm{~K}_{0.5} \mathrm{NbO}_{3}(\mathrm{NKN}) ;^{14,15}$ perovskite-like layer structured $\mathrm{A}_{2} \mathrm{~B}_{2} \mathrm{O}_{7}$ with super high $T_{c} ;{ }^{16,17}$ Aurivillius phase ferroelectric $\mathrm{Bi}_{3.15}$ $\mathrm{Nd}_{0.85} \mathrm{Ti}_{3} \mathrm{O}_{12} \quad(\mathrm{BNdT}){ }^{18}$ and multiferroic $\mathrm{Bi}_{0.89}$ $\mathrm{La}_{0.05} \mathrm{~Tb}_{0.06} \mathrm{FeO}_{3}$ (BLFO). ${ }^{19}$ In addition, the effects of grain size, point defects, texture, frequency and temperature on the $D-E$ loops are also discussed in order to provide a general guideline for the interpretation of the $D-E$ loops.

\section{Experimental}

PZT5A and PZT4D commercial ceramics coated with silver electrodes were supplied by Morgan Advanced Ceramics, UK. The other ceramics were sintered using Spark Plasma Sintering (SPS) (HPD $25 / 1 \mathrm{FCT}$, Germany). A heating rate of $100^{\circ} \mathrm{C} / \mathrm{min}$ was used for all materials.

Alumina powder (Sigma-Aldrich nanopowder 544833 ) was sintered at $1450^{\circ} \mathrm{C}$ for $3 \mathrm{~min}$ under $80 \mathrm{MPa}^{13}$ Multiferroric $\mathrm{Bi}_{0.89} \mathrm{La}_{0.05} \mathrm{~Tb}_{0.06} \mathrm{FeO}_{3}$ nanopowder was synthesized by the wet chemical method $^{20}$ and then sintered at $750{ }^{\circ} \mathrm{C}$ for $3 \mathrm{~min}$ under $50 \mathrm{MPa}$ with a protective layer of $\mathrm{CeO}_{2}$ powder. ${ }^{19}$ A commercial $\mathrm{Na}_{0.5} \mathrm{~K}_{0.5} \mathrm{NbO}_{3}$ powder (Ferroperm, Denmark, provided by St Jude Medical $\mathrm{AB}$, Järfälla, Sweden) was sintered at $850^{\circ} \mathrm{C}$ for 5 min under $100 \mathrm{MPa}^{15}$ Doped $\mathrm{BaTiO}_{3}$ powder (Syfer, UK) was SPSed at $1125^{\circ} \mathrm{C}$ for 5 min under $50 \mathrm{MPa}$. The bulk $\mathrm{Bi}_{3.15} \mathrm{Nd}_{0.85} \mathrm{Ti}_{3} \mathrm{O}_{12}$ ceramics were SPSed at $850^{\circ} \mathrm{C}$ and $1000^{\circ} \mathrm{C}$ for 3 min under a uniaxial pressure of $75 \mathrm{MPa}$. The corresponding samples are hereafter referred to as BNdT850, and BNdT1000, respectively. ${ }^{18}$ Non-textured $\mathrm{La}_{2} \mathrm{Ti}_{2} \mathrm{O}_{7}$ ceramic was sintered at $1350^{\circ} \mathrm{C}$ for 3 min under a uniaxial pressure of $100 \mathrm{MPa}$. Grain-oriented, textured $\mathrm{La}_{2} \mathrm{Ti}_{2} \mathrm{O}_{7}$ and $\mathrm{Nd}_{2} \mathrm{Ti}_{2} \mathrm{O}_{7}$ ceramics were prepared using a two-step SPS process. ${ }^{16}$ In the first step, the $\mathrm{La}_{2} \mathrm{Ti}_{2} \mathrm{O}_{7}$ and $\mathrm{Nd}_{2} \mathrm{Ti}_{2} \mathrm{O}_{7}$ powders were sintered in a graphite die with a diameter of $20 \mathrm{~mm}$ for $3 \mathrm{~min}$ under a pressure of $80 \mathrm{MPa}$ at $1250^{\circ} \mathrm{C}$. After this stage, the density of the ceramics was high $(\geq 98 \%)$, but the grain size was only slightly larger than that of the starting powders. In the second step, these sintered ceramics were placed in a graphite die with a diameter of $30 \mathrm{~mm}$ to sinter at $1350^{\circ} \mathrm{C}$ for $5 \mathrm{~min}$ under a pressure of $80 \mathrm{MPa}$. This caused the grains to grow in direction perpendicular 
to the applied pressure, resulting in a textured structure.

The bulk densities of the SPSed ceramics were measured by the Archimedes method. All the ceramics had high density ( $\geq 98 \%)$. The SPSed samples were annealed at $150^{\circ} \mathrm{C}$ below their sintering temperatures for 4 to $12 \mathrm{~h}$ to remove carbon and to reserve any reduction that took place during SPS. $\mathrm{X}$-ray diffraction $(\mathrm{XRD})$ patterns for the ceramics were obtained with an X-ray diffractometer (Siemens D5000) using $\mathrm{CuK}_{\alpha}$ radiation. All the materials were single phases, except PZT according to XRD results. The microstructures were observed using a scanning electron microscope (SEM; JEOL JSM 6300).

Electrodes for electric property measurements were applied by firing silver paste (Johnson Matthey,
E1100). The ferroelectric $I-E$ (current-electric field) and $D-E$ (electric displacement-electric field) loops were measured by a ferroelectric hysteresis measurement tester (NPL, UK) at different frequencies. This tester includes an amplifer (TREK model 610E or 609E-6), Function/Arbitrary Waveform Generator (Agilent 33120A) and a Low-noise Current Preamplifier (Stanford Research Systems, SR570). The measurement procedure involved the application of a triangular voltage waveform. The current from electric conductivity contribution has the same triangular shape of the voltage waveform. The current from the dielectric permittivity contribution is a constant value, being independent of the applied electric field, as shown further on. The total electric displacement was calculated by

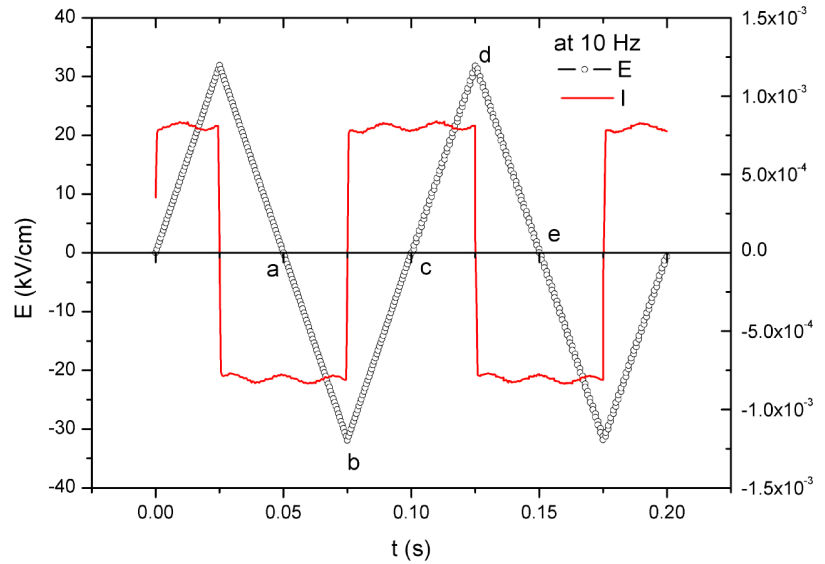

(a)

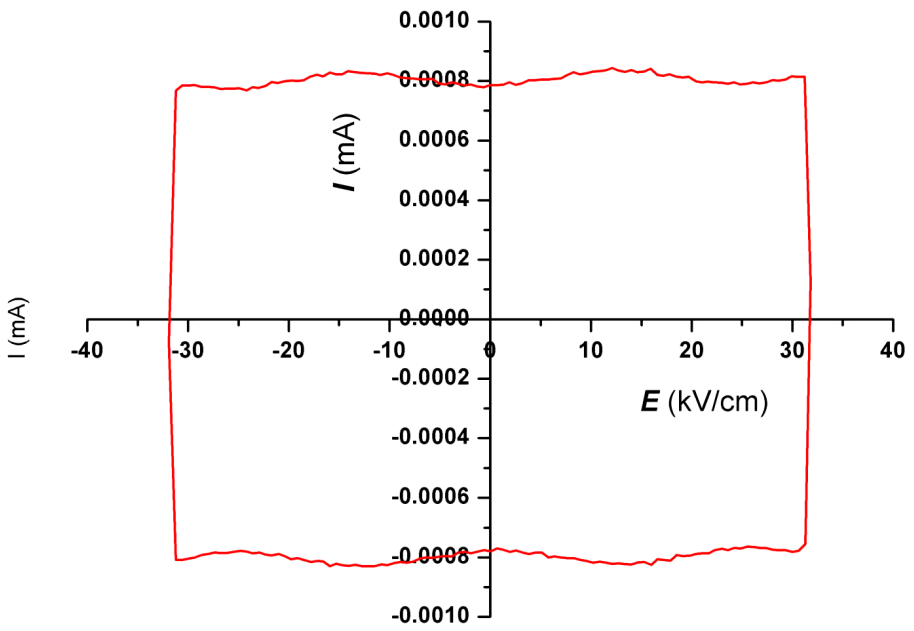

(b)

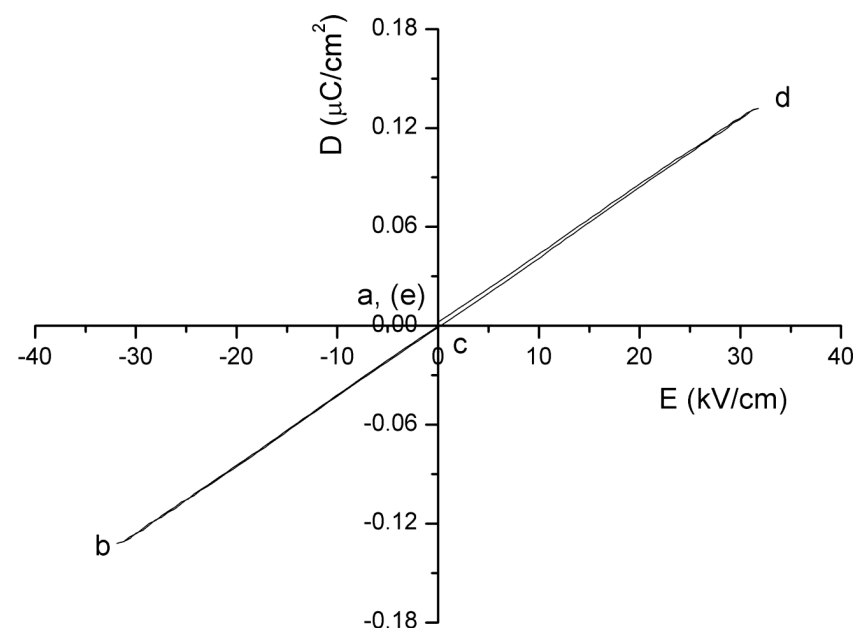

(c)

Fig. 1. Electric displacement-electric field $(D-E)$ loop measurement of $\mathrm{Al}_{2} \mathrm{O}_{3}$ ceramics at $10 \mathrm{~Hz}$ and $25^{\circ} \mathrm{C}$. (a) Electric field versus time and current versus time (b) current-electric field $(I-E)$ hysteresis loop, (c) electric displacement-electric field $(D-E)$ loop. 
integration of the total current over a cycle (a-b-c-d-e in Fig. 1(a)) in the middle of two complete cycles. The high temperature measurements were carried out in silicone oil.

\section{Results and Discussion}

\subsection{The contribution of dielectric permittivity}

Figure 1 shows the electric displacement of $\mathrm{Al}_{2} \mathrm{O}_{3}$ ceramic, which is that of a highly linear dielectric, but not ferroelectric. The electric resistivity of the alumina is very high $\left(>10^{15} \Omega \mathrm{cm}\right)$. There is no obvious contribution to current. The current in
Fig. 1(a) has only the contribution from the dielectric permittivity. A complete voltage cycle from a-bc-d-e was selected to analyze the effect of electric field $E$, on current $I$ (Fig. 1(b)). In the interval c-d (Fig. 1(a)), the electric field can be expressed as $E=\dot{E} t$, where $\dot{E}$ is rate of the applied electric field and $t$ is the time. The current $I$ (Fig. 1(b)) can be expressed as:

$$
\begin{aligned}
I & =\frac{d Q}{d t}=\frac{d}{d t}(C U)=\frac{d}{d t}\left(\frac{\varepsilon A E s}{s}\right)=\frac{d}{d t}(\varepsilon A \dot{E} t) \\
& =\varepsilon A \dot{E},
\end{aligned}
$$

where, $Q$ is the electric charge, $C$ the capacitance, $U$ the voltage, $E$ the electric field, $s$ the sample

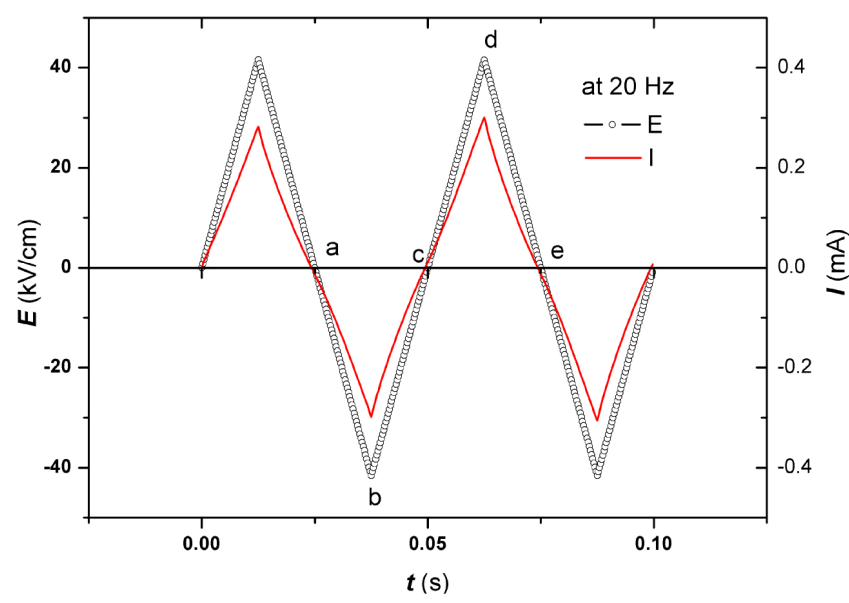

(a)

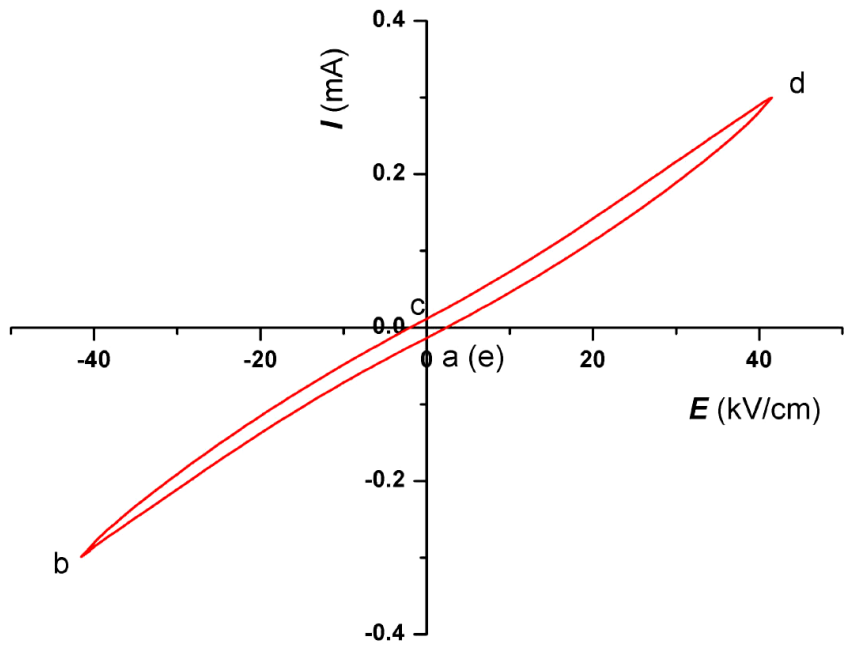

(b)

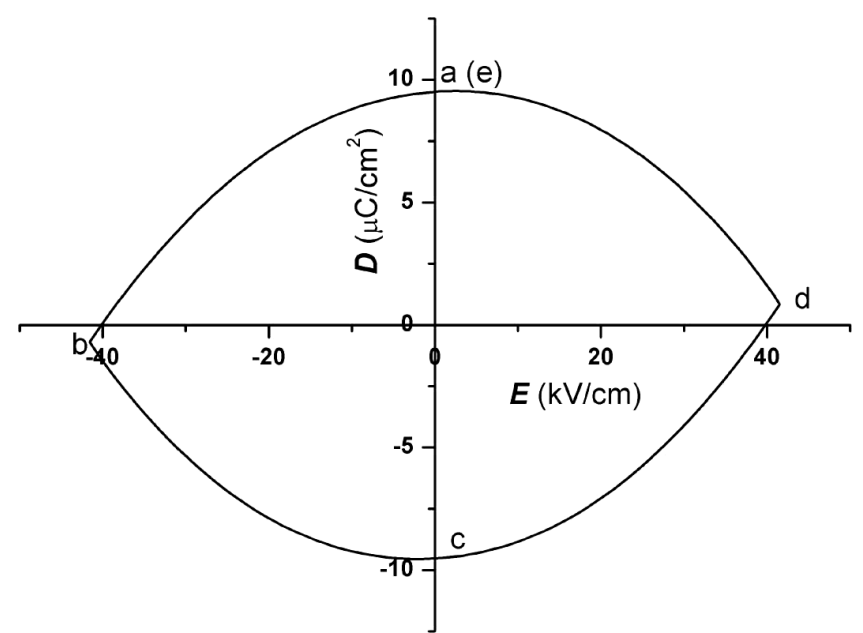

(c)

Fig. 2. Electric displacement-electric field $(D-E)$ loop measurement of BLFO ceramics at $20 \mathrm{~Hz}$ and $25^{\circ} \mathrm{C}$. (a) Electric field versus time and current versus time, (b) current-electric field $(I-E)$ hysteresis loop, (c) electric displacement-electric field ( $D-E)$ loop. 
thickness, $\varepsilon$ the dielectric permittivity, $A$ the sample area and $t$ the time. The previous equation shows that the current of $\mathrm{Al}_{2} \mathrm{O}_{3}$ depends on its dielectric permittivity, which is field independent (Fig. 1(b)). The $D-E$ loop (Fig. 1(c)) is obtained by integrating the current with respect to time in the interval a-bc-d-e and dividing by the area of the sample. The $D-E$ loop of $\mathrm{Al}_{2} \mathrm{O}_{3}$ is linear and non-hysteretic having only the contribution from dielectric permittivity.

\subsection{The contribution of electric conductivity}

Figure 2 shows the $D-E$ loop of BLFO using a triangular voltage waveform. With increasing electric field $E$ from c to d, the current $I$ is also increasing.
The voltage and current signals have the same waveform (Fig. 2(a)) as expressed by:

$$
I=\frac{U}{R}=\frac{E s}{R}=\frac{E A}{\rho},
$$

where $R$ is the electric resistance, $\rho$ the electric resistivity, $A$ the area and $s$ the thickness of the sample. For BLFO ceramics, the resistivity $\rho$ decreases with increasing voltage $U$. In the $I-E$ loop (Fig. 2(b)) the current has contributions from dielectric permittivity and electric conductivity, with the latter being the major contributor. This is because of the valence fluctuation of some of $\mathrm{Fe}$ ions from +3 to +2 in BLFO ceramics. ${ }^{19}$ In the $D-E$ loops of BLFO (Fig. 2(c)), there is no apparent contribution from domain switching.

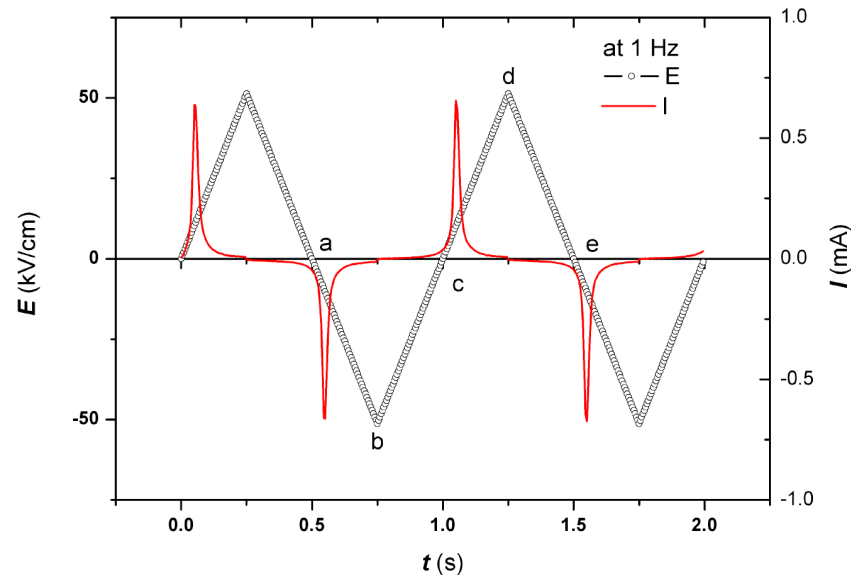

(a)

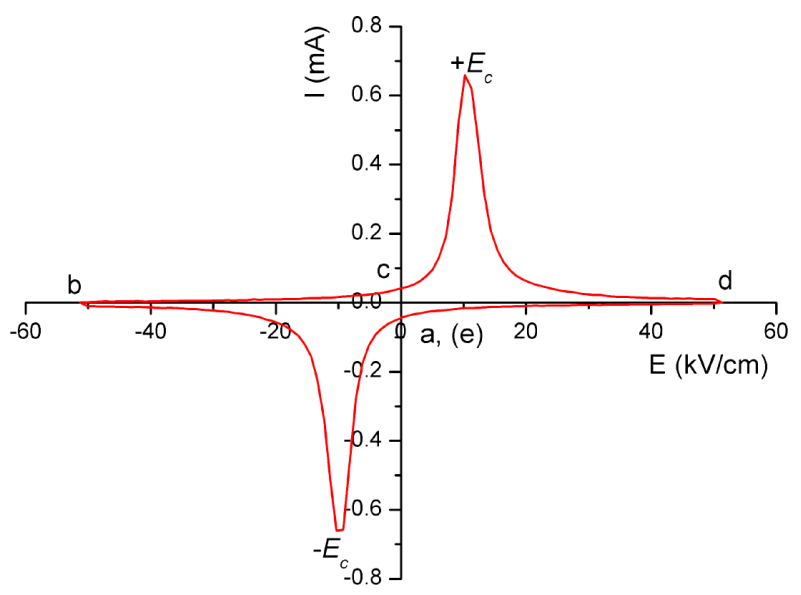

(b)

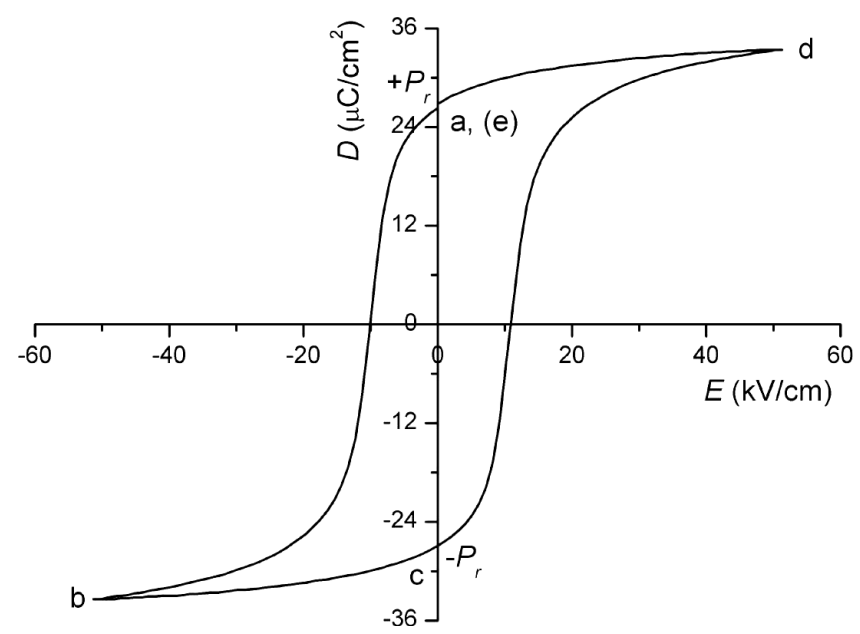

(c)

Fig. 3. Electric displacement-electric field $(D-E)$ loop measurement of NKN850 ceramics at $1 \mathrm{~Hz}$ and $25^{\circ} \mathrm{C}$. (a) Electric field versus time and current versus time (b) current-electric field $(I-E)$ hysteresis loop, (c) electric displacement-electric field ( $D-E)$ loop. 


\subsection{Domain switching current peak}

Figure 3 shows the ferroelectric hysteresis $(D-E)$ loop for NKN sintered at $850^{\circ} \mathrm{C}$. With increasing the electric field $E$ from point c to d (Fig. 3(a)), a current peak appears before the maximum electric field was applied (at point d). This is a clear evidence of ferroelectric domain switching. The current at the maximum applied field is very low compared to the peak current caused by domain switching (Fig. 3(b)). In this case, the domain switching contribution dominates the electric displacement compared to the contributions from electric conductivity and dielectric permittivity. The remnant polarization $P_{\mathrm{r}}$ is the $D$ at zero field (Fig. 3(c)). The coercive field $E_{\text {c }}$ can be identified as the electric field correspondent to the current peak (Fig. 3(b)) and in this case it coincides with the electric field correspondent at $D=0$ in the $D-E$ loop (Fig. 3(c)). The $E_{\mathrm{c}}$ determined from $D-E$ loops is not an absolute threshold field because if a low electric field is applied for a long time, the polarization will eventually switch. ${ }^{5,21}$ This is because the switching is thermally activated and therefore rate and temperature dependent. When reporting $E_{\mathrm{c}}$ it should be determined from the $I-E$ current peak for a saturated loop and the electric field rate and temperature should also be reported. ${ }^{22}$

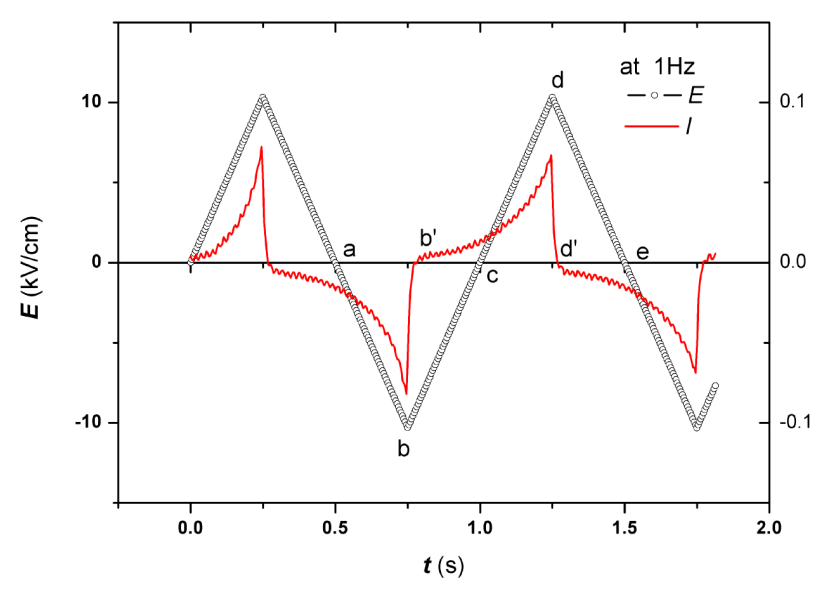

(a)

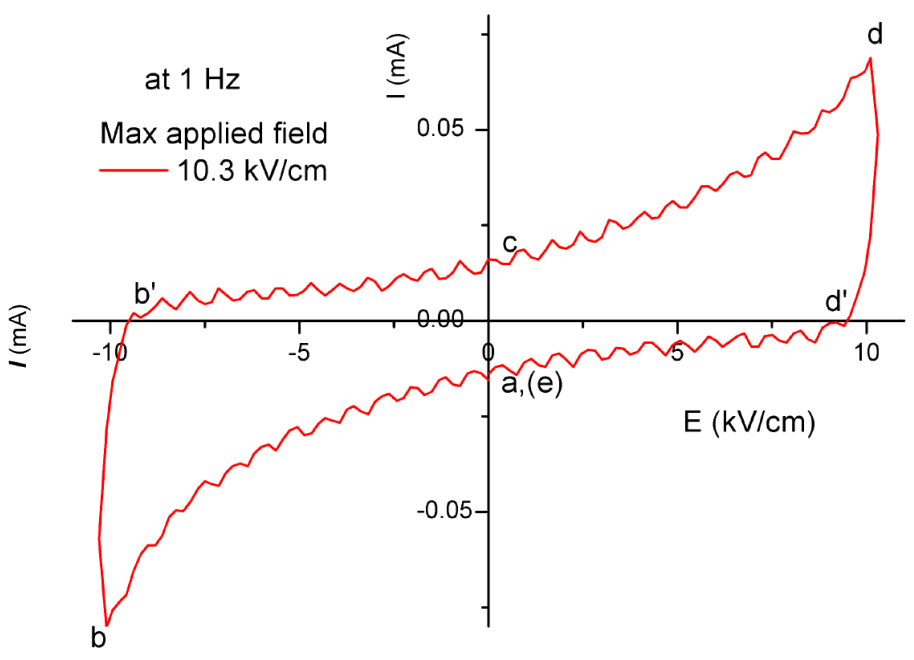

(b)

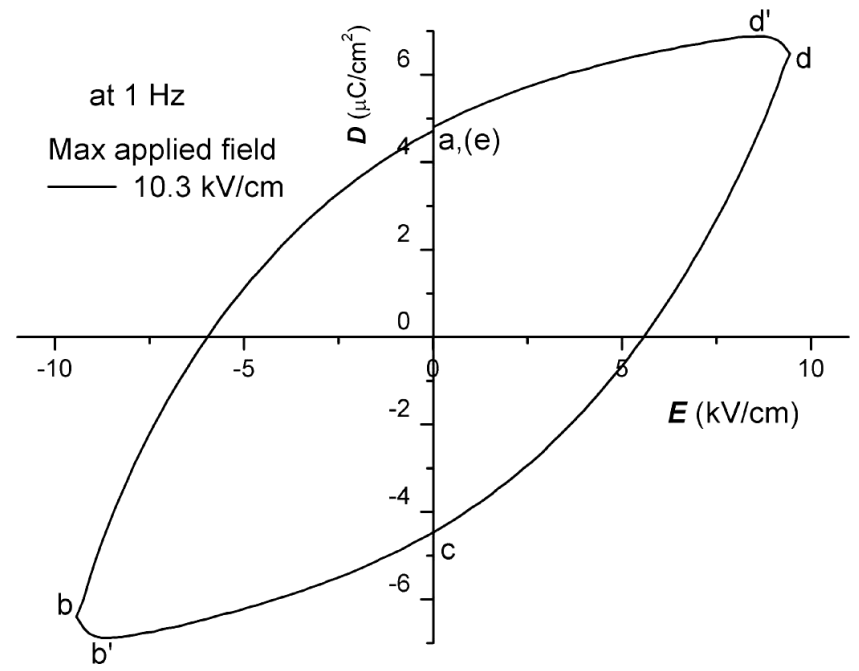

(c)

Fig. 4. Electric displacement-electric field $(D-E)$ loop measurement of PZT5A ceramics at $1 \mathrm{~Hz}$ and $25^{\circ} \mathrm{C}$. (a) Electric field versus time and current versus time, (b) current-electric field $(I-E)$ hysteresis loop, (c) electric displacement-electric field $(D-E)$ loop. 


\subsection{Saturation of $D-E$ loop ferroelectrics}

Figure 4 shows the ferroelectric hysteresis $(D-E)$ loop of PZT 5A. With the increasing field $E$ in the interval $\mathrm{c}-\mathrm{d}$, the current also increases (Fig. 4(a)). In the $I-E$ loop (Fig. 4(b)) the current peak may contain the contribution from domain switching beside the contribution from dielectric permittivity and electric conductivity. However, in this case it was not possible to ascertain the occurrence of domain switching only based on low field data (Fig. 4(b)) due to the fact that the $I-E$ loop displays a current peak in correspondence of the maximum electric field (Fig. 4(a)). Compared to the $I-E$ loop (Fig. 5(a)) at higher field, the current at maximum field is lower than the peak current in Fig. 4(b). This indicates that the current peak in Fig. 4(b) is due to the domain switching. In Fig. 4(c), it can be noticed that the $D$ value at point $\mathrm{d}^{\prime}$ where $I=0$ (Fig. 4(b)) is higher than that at point $d$. This is due to the contribution of electric conductivity in the current signal, which prevents a sudden drop in the current between points $\mathrm{d}$ to e as occurs when the contribution to the current comes solely from the dielectric permittivity as in the case of alumina (Fig. 1(c)). In Fig. 4(c), the $D-E$ loop obtained by integrating the current respect with time looks hysteretic, but the $E$ field at $D=0$ is not the $E_{\mathrm{c}}$ because the loop is presaturated. For the PZT 5A, the domain switching peak is clear when the field is higher than $10 \mathrm{kV} / \mathrm{cm}$ (Fig. 5(a)). The current peak positions and the remnant polarization $P_{\mathrm{r}}$ changed only slightly when the field was further increased (Figs. 5(a) and $5(\mathrm{~b}))$. This suggests that the $D-E$ loops are nearly saturated.

In many publications on ferroelectrics, $P_{\mathrm{r}}$ and $E_{\mathrm{c}}$ are wrongly reported because they are measured from pre-saturated $D-E$ loops, such as that shown in Fig. 4(c). It is also impossible to confirm that a new material is ferroelectric only based on a $D-E$ loop because even "bananas" can apparently also produce $D-E$ loops. ${ }^{11}$

\subsection{The effect of temperature}

It is very well known that temperature has a significant influence on the shape of the ferroelectric $D-E$ loops. This is due to the fact that the spontaneous polarization, $P_{\mathrm{s}}$, dielectric permittivity and conductivity of ferroelectric materials are temperature dependent. Figure 6 shows the $I-E$ and $D-E$ loops of a doped $\mathrm{BaTiO}_{3}$ ceramics at different temperatures. The current peaks corresponding to domain switching are clear in all of the $I-E$ curves (Fig. 6(a)). The current has contributions from the dielectric permittivity and domain switching. The absence of any tilt of the $I-E$ loops (Fig. 6(a)) indicates that the contribution of the electric conductivity is negligible even at high temperature. The current peaks values decreased with increasing temperature. The $D$ corresponding to the maximum applied field decreased with increasing temperature, which is consistent with the decrease of $P_{\mathrm{S}}$ at higher temperatures. Nonlinear and slightly

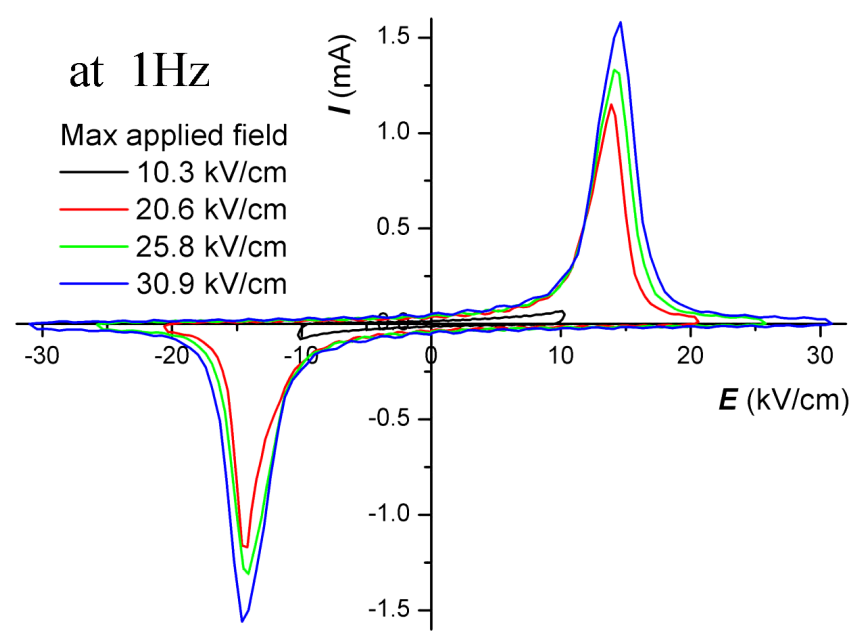

(a)

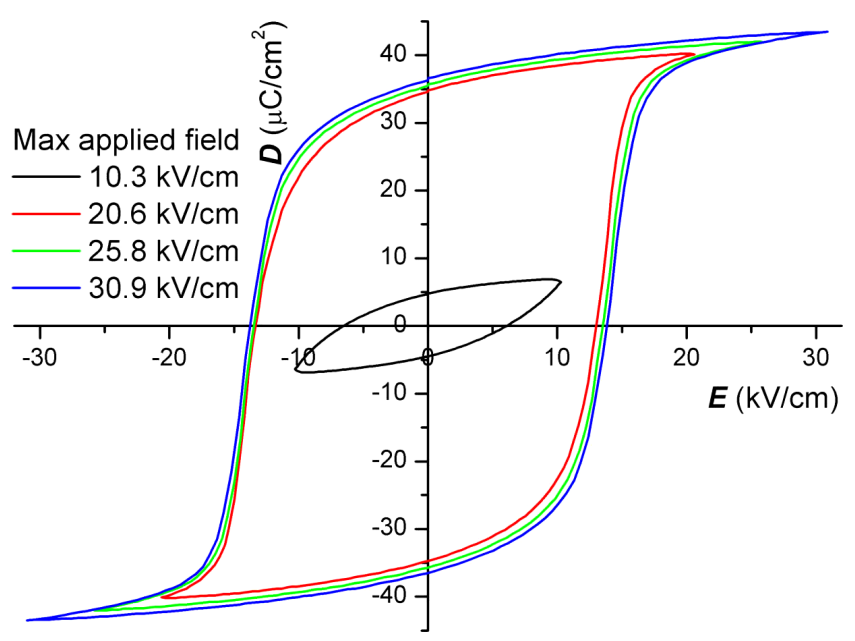

(b)

Fig. 5. (Color online) Electric displacement-electric field $(D-E)$ loop measurement of PZT5A at $1 \mathrm{~Hz}$ and $25^{\circ} \mathrm{C}$. (a) Currentelectric field $(I-E)$ hysteresis loop, (b) electric displacement-electric field $(D-E)$ loop. 


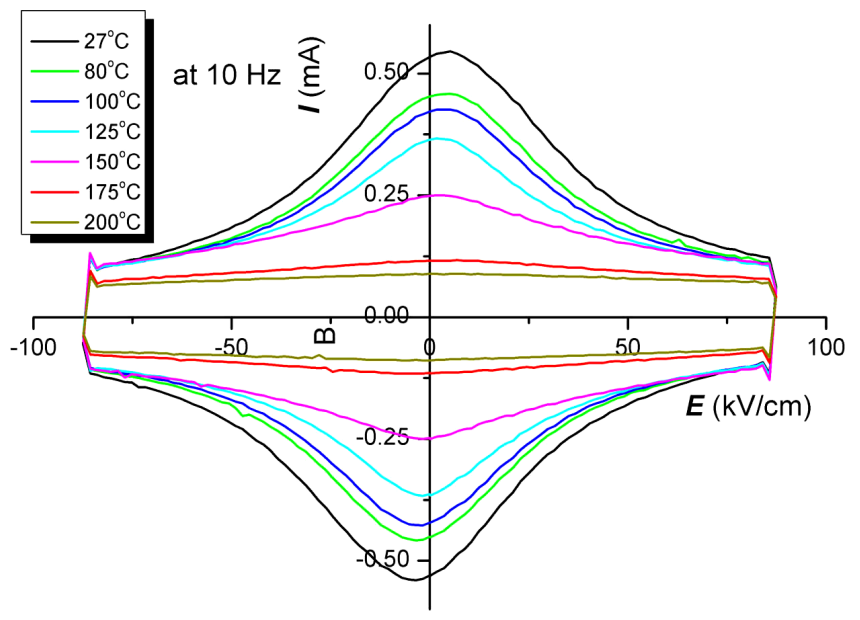

(a)

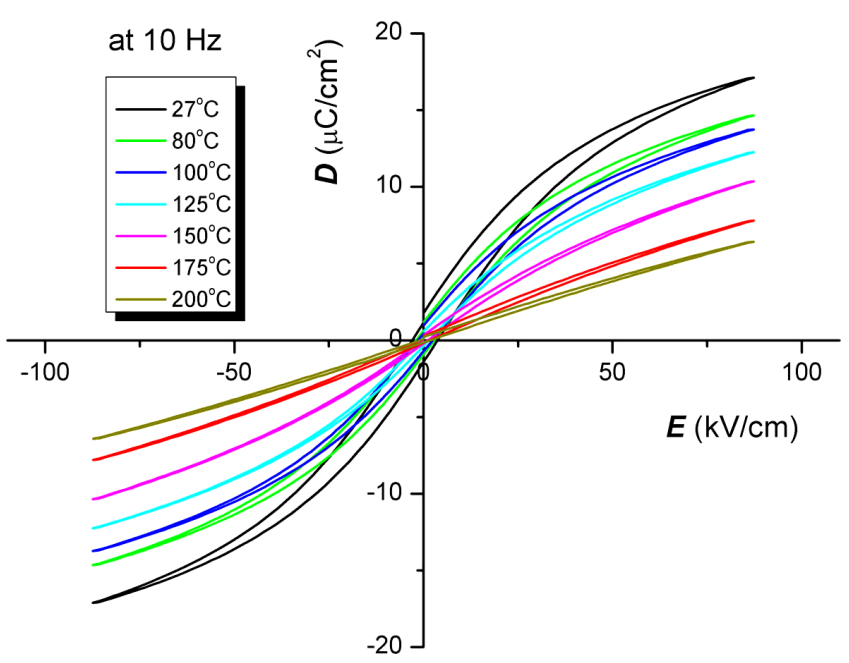

(b)

Fig. 6. (Color online) Electric displacement-electric field $(D-E)$ loop measurement of doped $\mathrm{BaTiO}_{3}$ ceramics at $10 \mathrm{~Hz}$ and different temperatures. (a) Current-electric field $(I-E)$ hysteresis loop, (b) electric displacement-electric field ( $D-E)$ loop.

hysteretic $D-E$ loops were observed even at $T>T_{\mathrm{c}}$ (Curie point $T_{\mathrm{c}}=118^{\circ} \mathrm{C}$ ). At $175^{\circ} \mathrm{C}$, the domain switching current peak is still present (Fig. 6(a)). This is attributed to the polar regions above $T_{\mathrm{c}}{ }^{23,24}$ The nature of the ferroelectricparaelectric phase transition of $\mathrm{BaTiO}_{3}$ has traditionally been recognized as displacive. However, it has been shown to be intermediate between displacive and order- disorder. ${ }^{23,24}$ At $257-297^{\circ} \mathrm{C}(530-570 \mathrm{~K})$, the polar nanoregions nucleate and begin to grow on cooling and at about $233^{\circ} \mathrm{C}(506 \mathrm{~K})$, the polar nanoregions begin to freeze out cooperatively. ${ }^{23}$ This is consistent with the domain switching peaks in the $I-E$ loop at $200^{\circ} \mathrm{C}(473 \mathrm{~K})$. The present doped $\mathrm{BaTiO}_{3}$ ceramic has very low $E_{\mathrm{c}}$ and $P_{\mathrm{r}}$ that give rise to quite slim $D-E$ loops, which makes the material a good candidate for dielectric energy storage. ${ }^{25,26}$
Figure 7 shows the Gibbs free energy $G$ versus electric displacement at different temperatures and zero electric field for ferroelectrics with first-order phase transformation. Below $T_{0}$, the two minimum positions of $G$ are related to the $+P_{\mathrm{s}}$ and $-P_{\mathrm{s}}$. That is why the ferroelectric phase is stable. Between $T_{\mathrm{o}}$ and $T_{\mathrm{c}}$, there is minimum of $G$ at $D=0$. It means that the paraelectric phase is pseudostable and the ferroelectric phase is stable. At $T_{\mathrm{c}}$, the ferroelectric phase and stable paraelectric can co-exist because they have the same Gibbs free energy. Between $T_{\mathrm{c}}$ and $T_{1}$, the paraelectric phase is stable and the ferroelectric phase is pseudostable. Between $T_{1}$ and $T_{2}$, paraelectric phase is stable and ferroelectric phase is unstable. Because of the two inflection points, the ferroelectric phase can be induced under an applied electric field. Above $T_{2}$, the inflection points

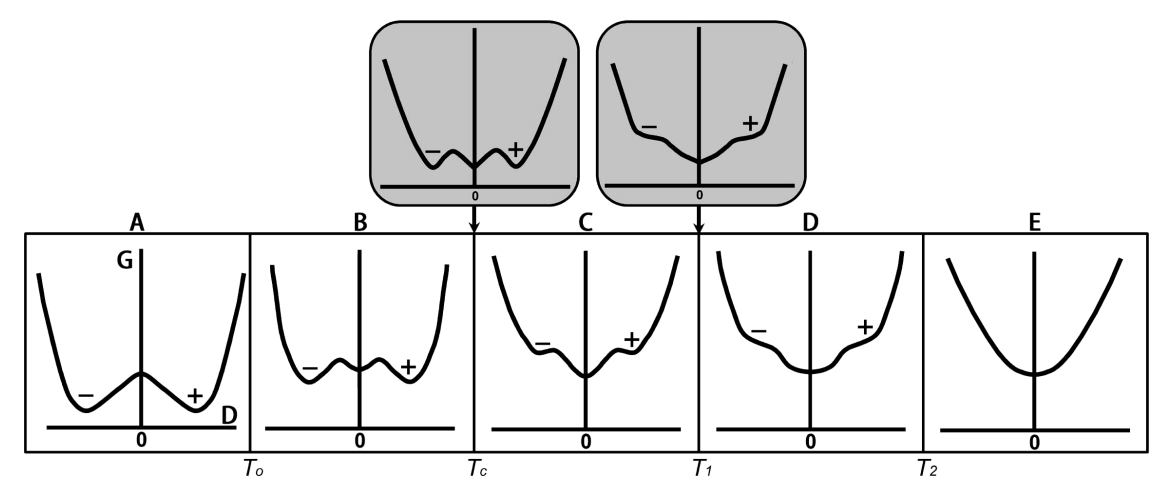

Fig. 7. Gibbs free energy $G$ versus electric displacement at different temperatures and zero electric field for ferroelectrics with firstorder phase transformation. 
disappear and the ferroelectric phase cannot be induced by an applied electric field. That is why the double hysteresis loops were observed in $\mathrm{BaTiO}_{3}$ above $T_{\mathrm{c}}$ and below $T_{2} \cdot{ }^{27}$

\subsection{The effect of oxygen vacancies}

Oxygen vacancies are the most important point defects in ferroelectric materials. PZT $4 \mathrm{D}$ is a hard ferroelectric because of coupling between the oxygen vacancy-acceptor doping dipoles and ferroelectric domain-walls. ${ }^{5,28}$ Figure 8 shows the $D-E$ loops of a PZT 4D. With the change in electric field $E$ from b to d, two current peaks were observed as indicated by $P 1$ and $P 2$ in Fig. 8 (a). The first peak $(P 1)$ is due to the switching of the dipoles formed by the oxygen vacancies (positively charged) with the acceptor dopant (negatively charged). The second peak $(P 2)$ is due to ferroelectric domain switching. The double peaks give rise to a characteristic pinched loop (Fig. 8(b)). With a further increase of the applied electric field the domain switching peaks become stronger than the peak related to oxygen vacancies (Fig. 8(c)).

\subsection{The effect of grain size and frequency}

Figure 9 shows $D-E$ loops for BNdT with different grain sizes. BNdT 850 was sintered at $850^{\circ} \mathrm{C}$ and had an equi-axed morphology. Its average grain size was about $160 \mathrm{~nm} .{ }^{18} \mathrm{BNdT} 1000$ was sintered at $1000^{\circ} \mathrm{C}$ and had plate-like grains. The average thickness was about $300 \mathrm{~nm}$ and the other two in-plane dimensions

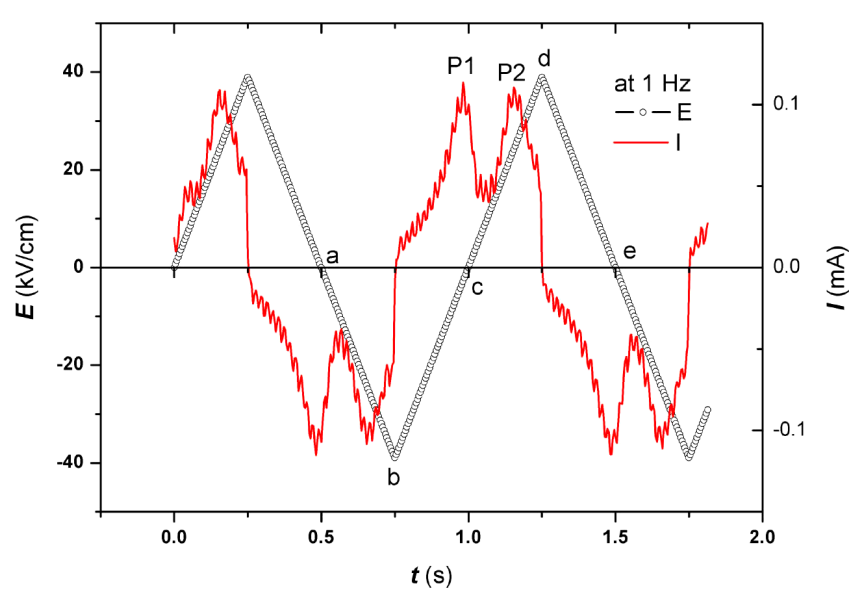

(a)

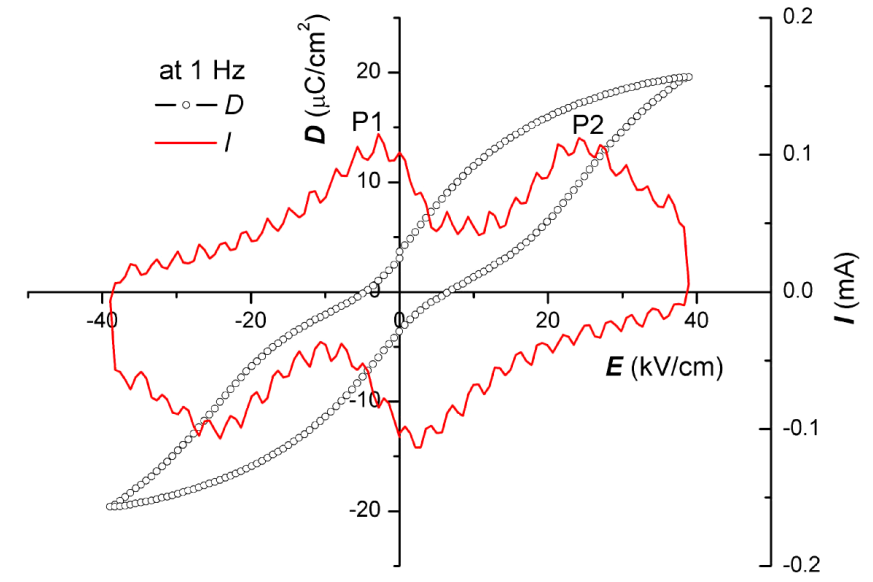

(b)

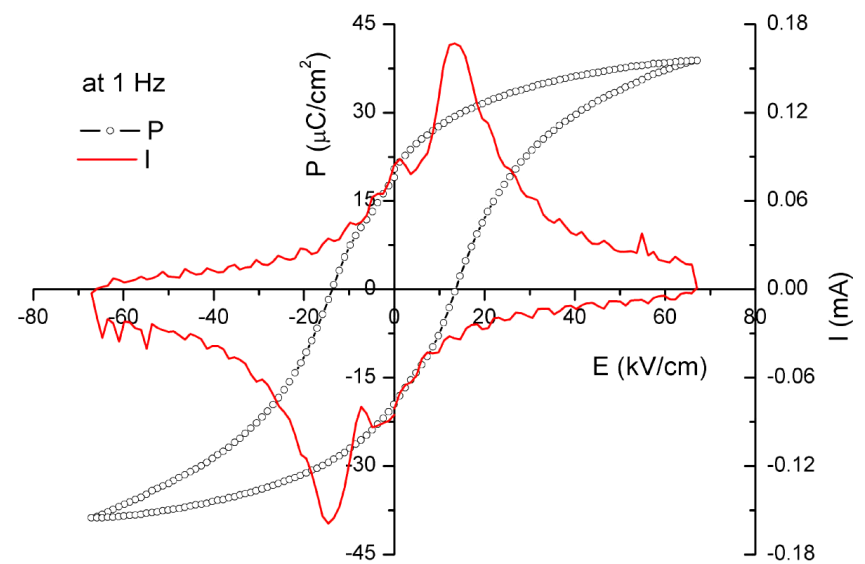

(c)

Fig. 8. Electric displacement-electric field $(D-E)$ loop measurement of PZT4D ceramics at $1 \mathrm{~Hz}$ and $25^{\circ} \mathrm{C}$. (a) Electric field versus time and current versus time at low field, (b) $I-E$ and field $D-E$ hysteresis loop at low field, (c) electric displacement-electric field $(D-E)$ loop. 


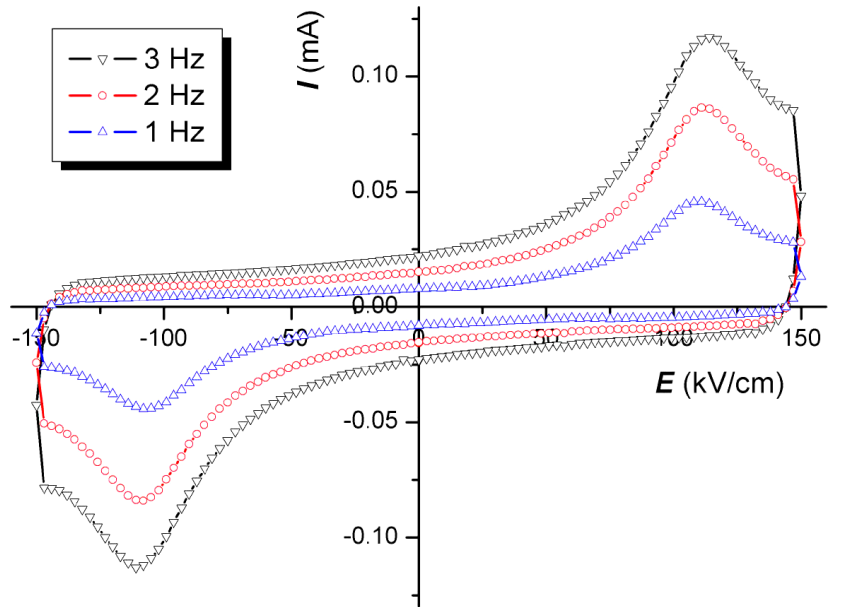

(a)

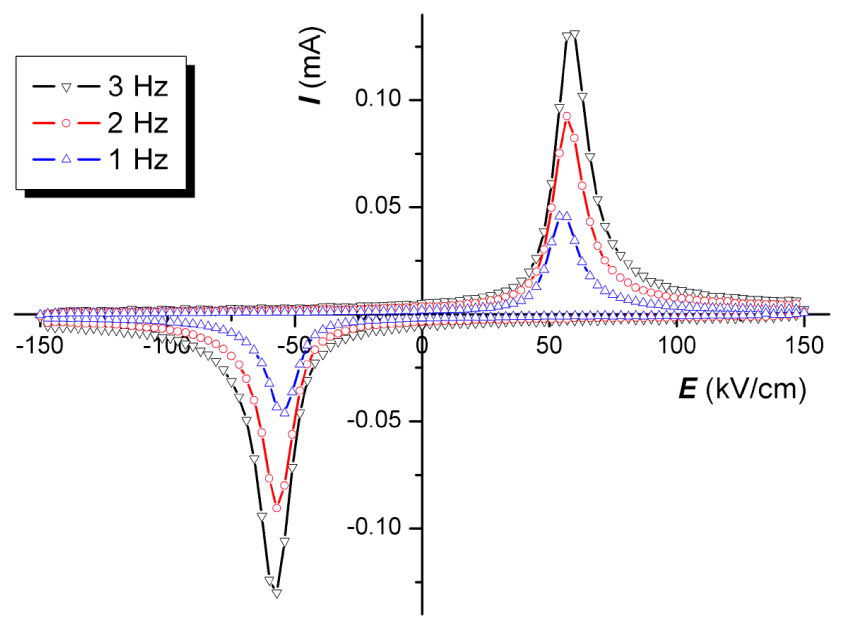

(c)

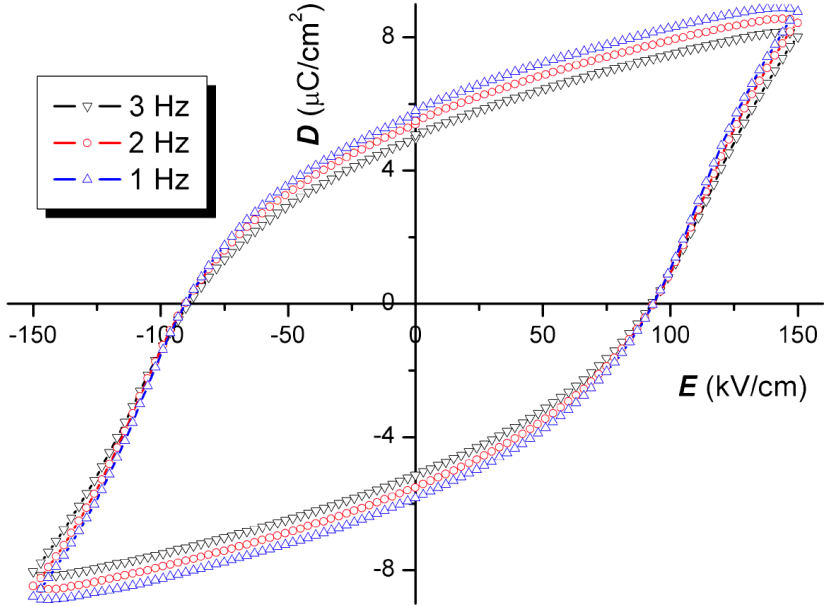

(b)

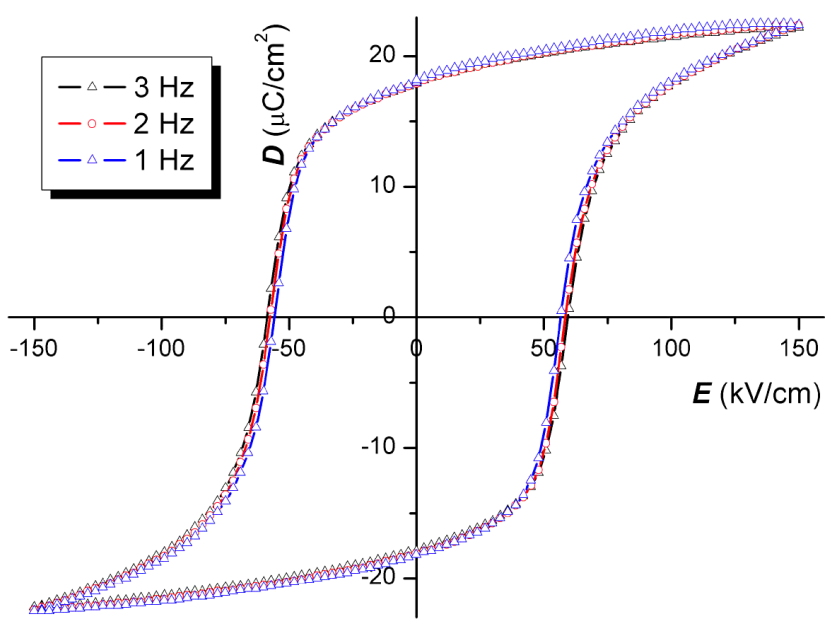

(d)

Fig. 9. (Color online) Electric displacement-electric field $(D-E)$ loop measurement of $\mathrm{BNdT}$ ceramics at $25^{\circ} \mathrm{C}$ and $\operatorname{different}$ frequencies: (a) $I-E$ hysteresis loop of BNdT850, (b) $D-E$ loops of BNdT850, (c) $I-E$ hysteresis loop of BNdT1000, (d) $D-E$ loops of BNdT1000.

were approximately $2000 \mathrm{~nm} \cdot{ }^{18}$ For both ceramics, increasing the frequency, caused the peak position to move to a higher field. The higher peak current value at higher frequency can be attributed to the higher rate of change of the electric field and the corresponding switching rate. ${ }^{22}$ The tilt of $I-E$ loop (Fig. 9(a)) can be attributed to the effect of conductivity. Because of the electric conductivity contribution, the electric field correspondent to the current peaks in $I-E$ loop $\left(E_{\mathrm{c}}\right)$ and the field correspondent at $D=0$ in the $D-E$ loops (Fig. 9(b)) do not coincide as in the case of NKN (Fig. 3). This further highlights why the coercive field should be defined as the field correspondent to the domain switching current peak. With increasing frequency,
$P_{\mathrm{r}}\left(D=P_{\mathrm{r}}\right.$ at zero $\left.E\right)$ decreases and the coercive field increases. Increasing frequency requires a greater applied driving force to compensate for the reduced contribution from thermal activation. It also reduces the total polarization switching that is achieved for the same maximum applied field. ${ }^{22}$ For PZT5H two orders of magnitude change in frequency produce a $15 \%$ change in $E_{\mathrm{c}}{ }^{22}$

The effect of grain size on $D-E$ loops can be observed by comparing the $I-E$ and $D-E$ loops relative to BNdT850 (Figs. 9(a) and 9(b)) and BNdT1000 (Figs. 9(c) and 9(d)). Based on the same field, BNdT1000 has higher $P_{\mathrm{r}}$ and lower $E_{\mathrm{c}}$ compared to BNdT850. In ferroelectric ceramics, the crystallite grains are randomly oriented and contain 
several ferroelectric domains. As the domains in one grain attempt to switch under the application of an electric field, they are constrained by the differently oriented neighboring grains. ${ }^{29}$ This makes the $E_{\mathrm{c}}$ of ceramics with fine grains much higher than ceramics with coarse grains. This is consistent with the fact that, the $E_{\mathrm{c}}$ of single crystals is lower than that of ceramics.

\subsection{The effect of texture}

For $\mathrm{La}_{2} \mathrm{Ti}_{2} \mathrm{O}_{7}$ and $\mathrm{Nd}_{2} \mathrm{Ti}_{2} \mathrm{O}_{7}$ textured ceramics, their XRD patterns from a surface perpendicular to the SPS pressing direction exhibited strong $(h 00)$ reflections. ${ }^{16}$ The grain orientation factor, $f$, was 0.80 and 0.82 for the $\mathrm{La}_{2} \mathrm{Ti}_{2} \mathrm{O}_{7}$ and $\mathrm{Nd}_{2} \mathrm{Ti}_{2} \mathrm{O}_{7}$ textured ceramics, respectively. ${ }^{16}$ The grains are platelike and oriented, which is consistent with the XRD data. The thickness direction of the grains corresponds to the long $a$-axis of their crystallographic unit cell, which is parallel to the pressing direction. Because their ferroelectric spontaneous polarization is along the $b$-axis, which is perpendicular $[\perp]$ to pressing direction, their ferroelectric switching is restricted to the plane perpendicular to pressing direction. ${ }^{16}$ Figure 10 shows the $I-E$ hysteresis loops of random grain oriented (non-textured) and textured $\mathrm{La}_{2} \mathrm{Ti}_{2} \mathrm{O}_{7}$ ceramics. For the textured ceramic the electric filed was applied along a direction $[\perp]$ to the pressing direction. The domain switching peaks were only observed in textured $\mathrm{La}_{2} \mathrm{Ti}_{2} \mathrm{O}_{7}$ ceramics, but not for non-textured $\mathrm{La}_{2} \mathrm{Ti}_{2} \mathrm{O}_{7}$ (Fig. 10). ${ }^{16}$ This is because the $E_{\mathrm{c}}$ of textured ceramics is lower

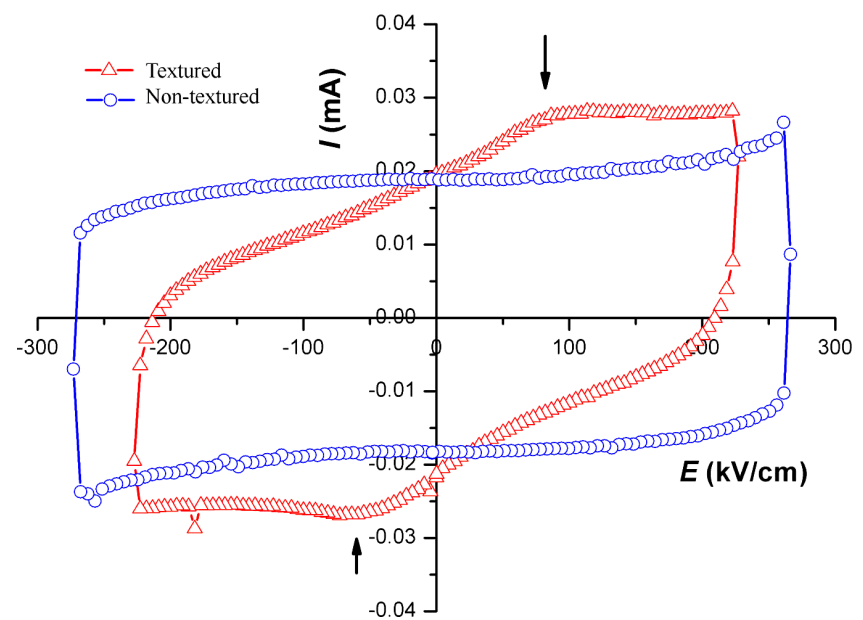

Fig. 10. Current-electric field $(I-E)$ hysteresis loop for (a) textured and (b) non-textured $\mathrm{La}_{2} \mathrm{Ti}_{2} \mathrm{O}_{7}$ ceramics at $10 \mathrm{~Hz}$ and $200^{\circ} \mathrm{C}$.

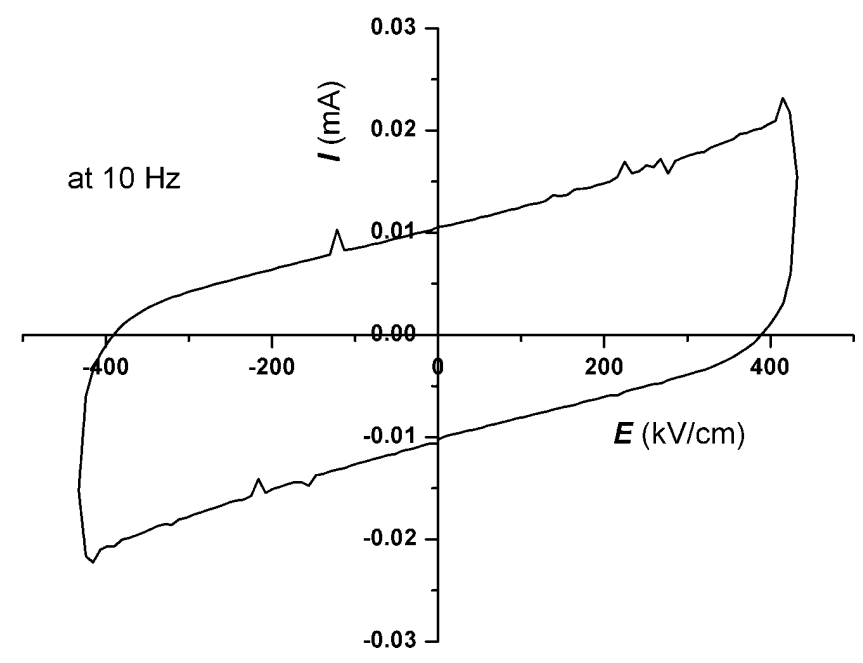

Fig. 11. Current-electric field $(I-E)$ hysteresis loop of textured $\mathrm{Nd}_{2} \mathrm{Ti}_{2} \mathrm{O}_{7}$ ceramics at $10 \mathrm{~Hz}$ and $200^{\circ} \mathrm{C}$.

than that of ceramics with randomly oriented grains due to their pseudo-single crystal structure. ${ }^{30}$ Figure 11 shows the $I-E$ hysteresis loops of the textured $\mathrm{Nd}_{2} \mathrm{Ti}_{2} \mathrm{O}_{7}$ ceramics. The electric field was applied along a direction $[\perp]$ to the pressing direction. Although there was no domain switching current peak in Fig. 11, in fact, domain switching in $\mathrm{Nd}_{2}$ $\mathrm{Ti}_{2} \mathrm{O}_{7}$ was still taking place as confirmed by nonzero piezoelectric constant $d_{33}$ after poling. ${ }^{16}$ The domain switching current peaks in Fig. 11 was masked by conductivity and dielectric permittivity contribution.

\section{Conclusions}

The present paper provides a clear understanding of the issues involved in the measurement and correct interpretation of ferroelectric properties. Hysteretic $D-E$ loops do not always provide solid evidence of ferroelectricity and therefore it is recommended that the presence of ferroelectricity must be confirmed by other independent methods, such as piezoelectric or pyroelectric measurements. The $I-E$ loops should be always provided to better interpret $D-E$ loops, and in particular the occurrence of ferroelectric switching. It is better to use a triangular voltage waveform to distinguish the effect of electric conductivity, dielectric permittivity, domain switching and rate effects and how those contributions can affect the shape of the $I-E$ and $D-E$ loops. When the contribution of the electric conductivity becomes dominant, rounded 
$D-E$ loops are generated, which cannot be used to estimate the coercive field and the remnant polarization. A peak in the current signal before reaching the maximum electric field indicates that domain switching is taking place. Furthermore, a clear method to define when $D-E$ loops are fully saturated is suggested. $D-E$ loops can be considered fully saturated when a further increase in the applied electric field does not produce a further increase in the $P_{\mathrm{r}}$, and $E_{\mathrm{c}}$. They become independent of the maximum field. Also, because switching is rate and temperature dependent, the field rate should also be given when reporting $E_{\mathrm{c}}$. In addition, it was shown that oxygen vacancies produced an additional current peak in $I-E$ loops and cause pinched $D-E$ loops below a certain electric field threshold. The effect of temperature on $D-E$ loops was discussed for $\mathrm{BaTiO}_{3}$, indicating that $P_{\mathrm{S}}$ reduces with increasing temperature and that domain switching current peaks may still be present above the Curie temperature, due to its relaxor behavior. By reducing the grain size, the coercive field $E_{\mathrm{c}}$ increases and the remnant polarization $P_{\mathrm{r}}$ decreases. The same trend on $E_{\mathrm{c}}$ and $P_{\mathrm{r}}$ was observed by increasing the frequency of the applied electric field. Textured ferroelectric structures present lower $E_{\mathrm{c}}$ than nontextured ferroelectric materials.

\section{Acknowledgements}

This work was supported by the UK Royal Society International Joint Project (2009/R2) and Xi'an Jiaotong University international incoming short visits (2008 and 2009).

\section{References}

1. G. H. Haertling, J. Am. Ceram. Soc. 82, 797 (1999).

2. A. von Hippel, R. G. Breckenridge, F. G. Chesley and L. Tisza, Eng. Chem. 38, 1097 (1946).

3. J. F. Scott, Science 315, 954 (2007).

4. T. M. Shaw, S. Trolier-McKinstry and P. C. McIntyre, Annu. Rev. Mater. Sci. 30, 263 (2000).

5. D. Damjanovic, Rep. Prog. Phys. 561, 1267 (1998).

6. C. B. Sawyer and C. H. Tower, Phys Rev. 35, 269 (1930).

7. Draft 16 of a Working document for a proposed standard to be entitled: IEEE standard definitions of terms associated with ferroelectric and related materials, IEEE Transactions on Ultrasonics, Ferroelectrics, and Frequency Control 50, 1613 (2003).

8. S. Dunn, J. Appl. Phys. 94, 5964 (2003).

9. S. Dunn and R. W. Whatmore, J. Euro. Ceram. Soc. 22, 825 (2002).

10. S. Dunn, A. P. De Kroon and R. W. Whatmore, J. Mater. Sci. Lett. 20, 179 (2001).

11. J. F. Scott, J. Phys. Condens. Mater. 20, 021001 (2008).

12. L. Pintillie and M. Alexe, Appl. Phys. Lett. 87, 112903, (2005).

13. F. Inam, H. Yan, D. J. Daniel, T. Peijs and M. J. Reece, Comp. Sci. Tech. 70, 947 (2010).

14. J. Rodel, W. Jo, K. T. P. Seifert, E. Anton, T. Granzow and D. Damjanovic, J. Am. Ceram. Soc. 92, 1153 (2009).

15. M. Eriksson, H. Yan, M. Nygren, M. J. Reece and Z. Shen, J. Mater. Res. 25, 240 (2010).

16. H. Yan, H. Ning, Y. Kan, P. Wang and M. J. Reece, J. Am. Ceram. Soc. 92, 2270 (2009).

17. H. Ning, H. Yan and M. Reece, J. Am. Ceram. Soc. 93, 1409 (2010).

18. H. Zhang, H. Yan, H. Ning, M. J. Reece, M. Eriksson, Z. Shen, Y. Kan and P. Wang, Nanotechnology 20, 385708 (2009).

19. Q. Jiang, F. Liu, C. Nan, Y. Lin, M. J. Reece, H. Yan, H. Ning and Z. Shen, Appl. Phys. Lett. 95, 012909 (2009).

20. S. M. Selbach, M. Einarsrud, T. Tybell and T. Grande, J. Am. Ceram. Soc. 90, 3430 (2007).

21. J. C. Burfoot and G. W. Tatlor, Polar Dielectric and Their Applications (Macmillan, London, 1979).

22. K. Chong, F. Guiu and M. J. Reece, J. Appl. Phys. 103, 014101 (2008).

23. E. Dul'kin, J. Petzelt, S. Kamba, E. Mojaev and M. Roth, Appl. Phys. Lett. 97, 032902 (2010).

24. B. Ravel, E. A. Stern, R. I. Vedrinskii and V. Kraizman, Ferroelectrics 206 and (207), 407 (1998).

25. B. Xu, P. Moses, N. G. Pai and L. E. Cross, Appl. Phys. Lett. 72, 593 (1998).

26. B. Chu, X. Zhou, K. Ren, B. Neese, M. Lin, Q. Wang, F. Bauer and Q. M. Zhang, Science 313, 334 (2006).

27. W. J. Merz, Phys Rev. 91, 513 (1953).

28. Q. Tan, J. Li and D. Viehland, Appl. Phys. Lett. 75, 418 (1999).

29. J. Y. Li, R. C. Rogan, E. Ustundag and K. Bhattacharya, Nature Mater. 4, 776 (2005).

30. H. Yan, M. J. Reece, J. Liu, Z. Shen, Y. Kan and P. Wang, J. Appl. Phys. 100, 076103 (2006). 